\title{
Hubungan Kebiasaan Membaca Label Gizi dengan Kejadian Hipertensi Pada Wanita Usia 40 Tahun
}

\section{Correlation Reading Habit of Nutritional Labels with Incidence of Hypertension in Women Aged $\geq 40$ Years}

\author{
Masyita Resti Nur Fauziyyah* ${ }^{1}$, Dea Dellyana Wahyutia Ady ${ }^{1}$
}

\begin{abstract}
ABSTRAK
Latar Belakang: Label gizi merupakan salah satu label pangan yang harus dicantumkan pada kemasan produk dengan tujuan untuk melindungi konsumen dalam memilih makanan yang aman. Kebiasaan membaca label gizi dapat mempengaruhi asupan zat gizi. Kebiasaan dalam membaca label gizi lebih banyak diterapkan oleh wanita, akan tetapi hal ini tidak digunakan untuk memutuskan pemilihan makanan kemasan. Hipertensi banyak terjadi pada wanita usia 40-60 tahun yang disebabkan karena asupan natrium yang berlebih.

Tujuan: Penelitian ini bertujuan untuk menganalisis hubungan kebiasaan membaca label gizi dengan kejadian hipertensi pada wanita usia 40 tahun.

Metode: Penelitian ini merupakan penelitian observasional dengan desain cross sectional dengan. Sampel penelitian ini adalah sebesar 70 orang. Penelitian ini dilakukan selama 3 hari untuk pengisian kuesioner. Pengukuran tekanan darah dilakukan pada hari pertama. Data kebiasaan membaca label gizi didapatkan melalui wawancara frekuensi membaca label gizi. Uji statistik yang dilakukan yaitu uji chi square.

Hasil: Hasil penelitian menunjukkan tidak adanya hubungan yang signifikan antara kebiasaan membaca label gizi dengan kejadian hipertensi $(\mathrm{p}=0,579)$

Kesimpulan: Kebiasaan membaca label gizi dengan kejadian hipertensi pada wanita usia 40 tahun tidak memiliki hubungan yang sigifikan.
\end{abstract}

Kata Kunci: label gizi, hipertensi, wanita usia 40 tahun.

\section{ABSTRACT}

Background: Nutrition labels are one of the food labels that must be included on product packaging with the aim to protecting consumers to choose safe foods. Reading habit of nutritional labels can affect nutrient intake. Reading habit of nutritional labels usually applied by women, but this is not used to decide on food selection. Incidence of hypertension often occurs in women aged 40-60 years because sodium intake exceeds requirements.

Objectives: This purpose of the research was to analyze the connectionsofreading habit of nutritional labels with incidence of hypertension in women aged $\geq 40$ years.

Methods: This research was an observational study with a cross sectional design. The sample of this research was 70 people. This research was conducted for 3 days for filling out the questionnaire. Blood pressure measurement is done on the first day. Data reading habit of nutrition label obtained from interviews frequency of reading nutrition labels. The statistical test performed was the chi square test.

Results: The results showed there was a correlation between the reading habit of nutritional labels with the incidence of hypertension $(p=0.579)$

Conclusions: Reading habit of nutritional labels with the incidence of hypertension in women aged $\geq 40$ years does not have a significant relationship.

Keywords: nutrition label, hypertension, women aged $\geq 40$ years. 
*Koresponden:

masyitaresti3@gmail.com

Masyita Resti Nur Fauziyyah

${ }^{1}$ Prodi S-1 Gizi, Fakultas Kesehatan Masyarakat, Universitas Airlangga, Kampus C, Mulyorejo, 60115, Surabaya, Jawa Timur, Indonesia

\section{PENDAHULUAN}

Hipertensi berasal dari bahasa latin yaitu hiper dan tension. Hiper artinya tekanan berlebih dan tension artinya tensi. Hipertensi atau tekanan darah tinggi merupakan suatu kondisi dimana seseorang mengalami peningkatan tekanan darah dalam jangka waktu yang lama. Hipertensi berkaitan dengan meningkatnya tekanan pada atrial sistemik baik diastolik maupun sistolik. Menurut Joint National Committee 8 (2014) seseorang dikatakan hipertensi jika tekanan darah $\geq 140 \mathrm{mmHg}$ dan $\geq 90 \mathrm{mmHg}$ (James et al. 2014). Hipertensi adalah peningkatan tekanan darah sistolik lebih dari $140 \mathrm{mmHg}$ dengan jeda waktu lima menit dan dalam keadaan cukup istirahat/tenang(Kemenkes 2014).

Tekanan sistolik menunjukan darah dipompa oleh jantung, sedangkan diatolik adalah fase dimana darah kembali lagi masuk ke jantung. Hipertensi dapat terjadi pada negara berpendapatan rendah, sedang dan tinggi. Hipertensi dapat terjadi pada siapa saja, dari berbagai kelompok umur dan status social ekonomi. Hipertensi merupakan faktor penyebab utama terjadinya penyakit di negara berpendapatan rendah, sedang, dan tinggi(Hussain et al. n.d.). Usia merupakan salah satu faktor terkuat terjadinya peningkatan tekanan darah. Pada usia 40-60 tahun peningkatan tekanan darah mulai terjadi dan puncaknya adalah saat usia $\geq 60$ tahun(Mahan 2017).

Hipertensi merupakan salah satu penyakit tidak menular. Gangguan sistem peredaran darah ini dapat menyebabkan kenaikan tekanan darah diatas normal. Salah satu penyebab terjadinya hipertensi adalah kebiasaan hidup yang kurang sehat. 600 juta penderita hipertensi di seluruh dunia, 3 juta diantaranya meninggal setiap tahunnya(WHO-ISH 2013). Menurut hasil Riskesdas 2007 prevalensi hipertensi adalah sebesar 25,8\%, pada tahun 2013 adalah sebesar 31,7\% dan terus meningkat pada tahun 2018 yaitu sebesar 34,1\%. Pengukuran dilakukan pada kelompok usia >18 tahun(Kemenkes RI 2018). Prevalensi hipertensi pada laki-laki lebih rendah dari wanita pada saat memasuki usia 40 tahun, hal ini berkaitan dengan faktor hormonal yang dialami wanita dan pola konsumsi yang tidak tepat(Geraci \& Geraci 2013).

Perubahan gaya hidup masyarakat berdampak terhadap perubaha pola konsumsi masyarakat. Pada era ini, masyarakat lebih cenderung mongonsumsi makanan luar rumah dan makanan kemasan(Hersey et al. 2013). Peningkatan konsumsi makanan luar rumah dan makanan kemasan tidak hanya terjadi pada usia remaja, melainkan pada wanita usia dewasa(Palupi, Naomi \& Susilo 2017). Makanan kemasan adalah salah satu makanan yang dibuat cengan daya tahan penyimpanan yang lama. Sebagian besar industri makanan memproduksi makanan dengan kadar natrium yang cukup tinggi, hal ini bertujuan untuk memperpanjang daya simpan makanan(Anderson et al. 2010). Hasil Survey Konsumsi Makanan Individu, penduduk Indonesia mengonsumsi garam sebanyak $3500 \mathrm{mg}$ setiap harinya(Prihatini, Permaesih \& Julianti 2017). Hal ini menunjukkan bahwa asupan natrium telah melebihi anjuran yang ditetapkan Permenkes Nomor 30 tahun 2013 yaitu tidak lebih dari $2000 \mathrm{mg}$ setiap harinya.

Head of Nutrition Center Nutrifood menyebutkan bahwa sedikit masyarakat Indonesia yang memperhatikan masalah komposisi makanan dan informasi nilai gizi pada kemasan makanan(Kairupan 2013). Salah satu informasi yang dicantumkan dalam kemasan makanan adalah label gizi(BPOM RI 2005). Kebiasaan membaca label gizi pada kemasan makanan memiliki korelasi terhadap pemilihan makanan yang sehat(Campos, Doxey \& Hammond 2011). Beberapa konsumen yang terbiasa memperhatikan label gizi belum tentu paham akan makna dari penggunaan label gizi(Cowburn \& Stockley 2005). Seseorang yang memahamicara membaca label gizi akan lebih waspada dalam memilih asupan yang akan dikonsumsi seperti salah satunya natrium, agar asupannya tidak melebihi batas yang ditentukan. Asupan natrium yang berlebih memberi dampak terhadap kejadian hipertensi, dimana hal tersebut memiliki korelasi terhadap kebiasaan membaca label gizi(J.E. et al. 2009).

\section{METODE}

Penelitian ini merupakan penelitian observasional dengan desain cross sectional. Populasi pada penelitian ini sebanyak 326 orang dengan usia 40. Penelitian ini menggunakan teknik systematic random sampling. Sampel minimal yang didapatkan menggunakan rumus Lemeshow adalah sebesar 70 orang responden dan harus memenuhi criteria inklusi(Kuntoro 2010). Kriteria inklusi pada penelitian ini antara lain, wanita berusia $\geq 40$ tahun, tinggal menetap di Desa Modong dan bersedia menjadi responden dalam penelitian ini.

Penelitian dilakukan selama satu bulan di Desa Modong, kecamatan Tulangan. Setiap responden akan diadakan 3 kali pertemuan, yaitu dua hari pada hari biasa dan satu hari pada hari libur. Pertemuan pada hari pertama diawali dengan pengukuran tekanan darah oleh petugas kesehatan dari puskesmas, pengukuran tekanan darah di lakukan sebanyak 2 kali dan dilanjutkan dengan pengisian kuesioner terkait karakteristik, kebiasaan membaca label gizi, pengetahuan label gizi, aktivitas fisik dan stess. Pada hari ke dua dan ke tiga dilanjutkan untuk pengisian kuesioner pola makan dan pada hari ke tiga responden diberikan leaflet dan edukasi tentang gizi seimbang serta hipertensi. Pengambilan data dilakukan selama kurang lebih 30 menit pada hari pertama dan 15 menit pada hari ke duadan ke tiga. Proses pengambilan data akan dilakukan pada pukul 14.00-16.00 WIB. 
Data yang digunakan adalah data primer dan data sekunder. Data sekunder yang dikumpulkan adalah gambaran umum puskesmas serta daftar nama wanita usia 40 tahun. Data primer yang dikumpulkan adalah kebiasaan membaca label gizi, asupan natrium dan status hipertensi. Pengambilan data primer dibantu menggunakan media kuesioner. Data yang terkumpul akan diolah menggunakan software SPSS 21.0 For Windows. Data tersebut akan dianalisis menggunakan uji chi square dengan derajat kepercayaaan $95 \%$ untuk melihat hubungan antara kebiasaan membaca label gizi dengan kejadian hipertensi.

Penelitian ini telah lulus uji etik dari Komisi Etik Penelitian Fakultas Kesehatan Masyarakat Universitas Airlangga dengan nomor sertifikat 120/EA/KEPK/2019 tanggal 17 April 2019.Semua responden telah menyetujui untuk ikut serta dalam penelitian ini dan menandatangani informed consent.

\section{HASIL DAN PEMBAHASAN}

Karakteristik Responden

Karakteristik responden yang diteliti pada penelitian ini adalah usia, tingkat pendidikan, pekerjaan dan tingkat penghasilan. Karakteristik tingkat pendidikan akan mempengaruhi pekerjaan seseorang dan jenis pekerjaan seseorang akan memberikan dampak pada tingkat penghasilannya. Karakteristik responden dapat dilihat pada Tabel 1.

Tabel 1. Distribusi Frekuensi Karakteristik Responden

\begin{tabular}{|c|c|c|}
\hline Karakteristik Responden & $\begin{array}{c}\text { Frekuensi } \\
\text { (n) }\end{array}$ & $\begin{array}{c}\text { Persentase } \\
(\%)\end{array}$ \\
\hline \multicolumn{3}{|l|}{ Usia } \\
\hline 40-49 tahun & 40 & 57,1 \\
\hline 50-59 tahun & 30 & 42,9 \\
\hline Total & 70 & 100,0 \\
\hline \multicolumn{3}{|l|}{ Tingkat Pendidikan } \\
\hline Tidak Tamat SD & 0 & 0,0 \\
\hline Tamat SD & 17 & 24,3 \\
\hline Tamat SMP & 26 & 37,1 \\
\hline Tamat SMA & 19 & 27,1 \\
\hline Tamat PT & 8 & 11,4 \\
\hline Total & 70 & 100,0 \\
\hline \multicolumn{3}{|l|}{ Pekerjaan } \\
\hline Tidak bekerja & 42 & 58,6 \\
\hline Pegawai & 2 & 2,9 \\
\hline Wiraswasta & 23 & 32,9 \\
\hline Petani/Nelayan/Buruh & 4 & 5,7 \\
\hline \multicolumn{3}{|l|}{ Tingkat Penghasilan } \\
\hline \multicolumn{3}{|l|}{ UMK Sidoarjo 2018} \\
\hline$(\geq 3.800 .000,00)$ & 2 & 2,9 \\
\hline \multicolumn{3}{|l|}{ Di bawah UMK } \\
\hline$(<3.800 .000,00)$ & 68 & 97,1 \\
\hline Total & 70 & 100,0 \\
\hline
\end{tabular}

Responden dalam penelitian ini sebagian besar berusia 40-49 tahun sebesar 57,1\% atau sebanyak 40 orang. Nilai minimun usia responden adalah 40 dan nilai maksimum usia responden adalah 57 tahun. Rata-rata usia responden adalah 45,8 dengan standart deviasi $\pm 4,9$ (Tabel 1).

Tingkat pendidikan terakhir wanita di Desa Modong yang menjadi responden meliputi $11,4 \%$ atau sebanyak 8 orang responden tamat perguruan tinggi, 27,1\% atau sebanyak 19 orang responden tamat SMA, $37,1 \%$ atau sebanyak 26 orang responden tamat SMP dan 24,3\% responden tamat SD atau sebanyak 17 orang responden. Tingkat pendidikan terakhir dapat memengaruhi pemahaman respnden dalam membaca label gizi. Seseorang dengan pendidikan yang lebih tinggi, akan memiliki wawasan lebih baik dalam memahami label gizi dari pada seseorang yang memiliki tingkat pendidikan lebih rendah(Adilin et al. 2015) (Tabel 1).

Umumnya pendidikan mempengaruhi jenis pekerjaan seseorang. Pada penelitian ini menunjukan hasil bahwa sebagian besar responden adalah seorang ibu rumah tangga. Responden yang tidak bekerja adalah sebesar 58,6\% atau sebanyak 42 responden, 23 orang responden atau sebesar 32,9\% memiliki profesi sebagai wiraswasta dan $5,7 \%$ dari total responden bekerja sebagai petani atau nelayan. Hanya ada 2 orang responden atau sebesar 2,9\% yang bekerja sebagai Pegawai Negeri Sipil (PNS) atau sebagai pegawai pabrik. Seseorang dengan pekerjaan yang lebih tinggi, dapat mempengaruhi tingkat pendapatan responden. Pendapatan memiliki 
pengaruh yang cukup besar dalam hal pemilihan bahan makanan. Bahan makanan yang dikonsumsi akan mempengaruhi seberapa banyak uang yang harus dikeluarkan untuk membeli bahan makanan tersebut. Dapat dikatakan bahwa tingkat pendapatan mampu mempengaruhi responden dalam memilih dan membeli bahan makanan(Notoatmodjo 2012) (Tabel 1).

Penghasilan yang diperoleh responden dalam satu bulan sebagian besar masih di bawah UMK Kabupaten Sidoarjo, yaitu sebesar Rp. 3.800.000. Sebanyak 68 orang responden atau sebesar 97,1\% memiliki penghasilan di bawah UMK. Hanya 2 orang responden yang memiliki penghasilan sesuai UMK atau sebesar 2,9\%. Ratarata penghasilan responden adalah sebesar Rp. 1.550 .142 dengan standart deviasi \pm 110.273 . Nilai minimun penghasilan responden adalah Rp. 0 karena responden hanya menjadi ibu rumah tangga. Sedangkan nilai maksimum penghasilan responden adalah sesuai dengan UMK Kabupaten Sidoarjo yaitu sebesar Rp.

3.800.000 karena beberapa dari responden bekerja sebagai Pegawai Negeri Sipil (PNS) dan pegawai pabrik (Tabel 1).

Berdasarkan hasil wawancara menggunakan kuesioner kebiasaan membaca label gizi diperoleh hasil sebanyak 6 orang responden atau sebesar $10 \%$ dari total responden memiliki kebiasaan membaca label gizi secara rutin. Sedangkan 40 orang responden atau 28,6\% dari total responden jarang membaca label gizi dan 24 orang respondenatau sebesar $61,4 \%$ dari total responden tidak pernah membaca label gizi. Faktor-faktor yang mempeharuhi kebiasaan membaca label gizi diataranya adalah pengetahuan terkait cara membaca dan memahami label gizi. Sebagian besar responden tidak pernah membaca label gizi karena tidak memiliki cukup banyak waktu dan tidak paham fungsi label gizi. Distribusi pengetahuan responden terkait label gizi dapat dilihat pada Tabel 2.

Tabel 2. Distribusi Responden Berdasarkan Kebiasaan Membaca Label Gizi

\begin{tabular}{|c|c|c|}
\hline Kebiasaan Membaca Label Gizi & $\begin{array}{c}\text { Frekuensi } \\
\text { (n) }\end{array}$ & $\begin{array}{c}\text { Presentase } \\
(\%)\end{array}$ \\
\hline Sering & 6 & 8,6 \\
\hline Jarang & 40 & 57,1 \\
\hline Tidak Pernah & 24 & 43,3 \\
\hline Total & 70 & 100,0 \\
\hline
\end{tabular}

Hasil uji statistik menunjukkan bahwa sebagian besar responden tidak memahami cara membaca label gizi yaitu sebanyak 46 orang responden atau sebesar $65,7 \%$. Sedangkan responden yang memahami cara membaca label gizi adalah sebanyak 24 orang responden atau sebesar 34,4\%.Responden yang memiliki pengetahuan tidak baik, cenderung tidak pernah membaca label gizi (Tabel 3).

Tabel 3. Distribusi Responden Berdasarkan Pengetahuan dalam Memahami Label Gizi

\begin{tabular}{lcc}
\hline Kebiasaan Membaca Label Gizi & Frekuensi & $\begin{array}{c}\text { Presentase } \\
(\boldsymbol{\%})\end{array}$ \\
\hline Baik & $(\mathbf{n})$ & 34,3 \\
\hline Tidak Baik & 24 & 65,7 \\
\hline Total & 46 & 100,0 \\
\hline
\end{tabular}

Status Hipertensi responden diperoleh dari hasil pengukuran tekanan darah secara langsung oleh petugas kesehatan dari puskesmas. Tekanan darah diukur menggunakan alat tensimeter digital dengan ketelitian \pm 3 mmHg. Klasifikasi hipertensi yang digunakan di Indonesia yaitu Joint National Committee (JNC8) tahun 2014. Dari hasil pengukuran dan klasifikasi tersebut, didapatkan 37 orang responden atau sebesar 52,9\% mengalami hipertensidan 33 orang responden atau sebesar 47,1\% tidak mengalami hipertensi. Rata-rata tekanan darah sistolik responden adalah $134,83 \mathrm{mmHg}$ dengan standart deviasi $\pm 12,15$. Sedangkan rata-rata tekanan darah diastolik sebesar $87,8 \mathrm{mmHg}$ dengan standart deviasi $\pm 5,01$. Nilai minimum tekanan darah dari responden adalah 85/70 $\mathrm{mmHg}$ dan maksimum tekanan darah responden adalah 159/96 $\mathrm{mmHg}$

Kebiasaan membaca label gizi dihubungkan dengan kejadian hipertensi pada responden dengan tujuan untuk mengetahui ada atau tidaknya hubungan antara kebiasaan membaca label gizi dengan kejadian hipertensi. Berdasarkan perhitungan menggunakan SPSS diperoleh hasil seperti yang tercantum pada Tabel 4. 
Tabel 4. Hubungan Kebiasaan Membaca Label Gizi dengan Kejadian Hipertensi pada Wanita Usia 40 Tahun Kebiasaan Membaca Label Gizi Status Hipertensi

Total Tidak Hipertensi Hipertensi
$P$ Value

\begin{tabular}{lccccccc} 
& $\mathrm{n}$ & $\%$ & $\mathrm{n}$ & $\%$ & $\mathrm{n}$ & $\%$ & \\
\cline { 1 - 5 } Sering & 3 & 9,1 & 3 & 8,1 & 6 & 8,6 \\
\hline Jarang & 18 & 54,5 & 16 & 43,2 & 36 & 48,6 \\
\hline Tidak Pernah & 12 & 36,4 & 18 & 48,6 & 30 & 42,8 \\
\hline Total & 33 & 100 & 37 & 100 & 70 & 100,0 \\
\hline
\end{tabular}

Indonesia merupakan salah satu negara dengan konsumsi makanan kemasan tertinggi di dunia. Salah satu hal yang perlu diperhatikan dalam konsumsi makanan kemasan adalah label gizi. Label gizi merupakan informasi yang ditujukan kepada masyarakat untuk memberikan informasi terkait manfaat dan kandungan gizi makanan dalam kemasan tersebut. Membaca label gizi makanan kemasan bertujuan untuk melindungi konsumen dari konsumsi makanan yang tidak aman, selain itu konsumen dapat mengetahui kebenaran informasi produk terutama produk yang memiliki klaim terkait gizi dan kesehatan(BPOM RI 2016).

Penelitian dilakukan pada wanita usia dewasa di Desa Modong, KecamatanTulangan. Dalam penelitian ini, kebiasaan membaca label gizi dinilai berdasarkan frekuensi responden dalam membaca label gizi. Selain itu, kebiasaan membaca label gizi juga dipengaruhi oleh pengetahuan responden dan membaca label gizi juga menentukan pemilihan pangan kemasan. Salah satu faktor yang mempengaruhi pengetahuan seseorang adalah pendidikan. Tingkat pendidikan dapat mempengaruhi kebiasaan untuk membaca label gizi(Castillo, Royo \& Moya 2012).

Pada penelitian ini sebagian besar responden yang mengalami hipertensi yaitu sebanyak 37 orang responden atau sebesar 52,9\% dari total responden. Angka tersebut menunjukan hasil yang lebih tinggi dibandingkan dengan prevalensi hipertensi yang terjadi di Tulangan pada tahun 2018 yaitu sebesar 35,7\%(Badan Pusat Statistik 2017).

Klasifikasi penentuan kebiasaan membaca label gizi pada responden didapatkan berdasarkan frekuensi kebiasaan membaca label gizi. Sedangkan data hipertensi didapatkan darihasil pengukuran secara langsung tekanan darah responden menggunakan tensimeter. Hasil uji korelasi chi square antara kebiasaan membaca label gizi dengan kejadian hipertensi didapatkan hasil $(\mathrm{p}=0,579)$. Dapat disimpulkan bahwa tidak terdapat hubungan yang signifikan antara kebiasaan membaca label gizi dengan kejadian hipertensi pada responden.

Hasil tersebut menunjukan bahwa kebiasaan membaca label gizi bukan salah satu faktor yang mempengaruhi status hipertensi responden secara langsung. Hal serupa juga terjadi pada penelitian yang dilakukan di New York, bahwa tidak terdapat hubungan $(p=0,267)$ antara penggunaan label gizi dengan kejadian hipertensi. Hal tersebut dikarenakan masyarakat hanya tertarik untuk membaca label gizi, tapi tidak digunakan untuk memilih bahan makanan kemasan. Hasil tersebut juga berlakubagi responden yang hipertensi maupun tidak hipertensi(Elfassy et al. 2015). Penelitian lain juga menunjukan bahwa sebesar 56,2\% responden tidak membaca label kemasan maupun label gizi sebagai bahan pertimbangan membeli pangan kemasan ${ }^{21}$. Penelitian lain juga menunjukan bahwa wanita usia 20-60 tahun hanya membacalabel gizi dikarenakan penyakit tertentu. Karena pada wanita yang menginjak usia menopouse, lebih beresiko mengalami penyakit cardiovaskular. Oleh karena itu pada wanita yang jarang membaca label gizi lebih beresiko mengalami penyakit tertentu, salah satunya hipertensi(Zhang et al. 2017).

Tujuan dan manfaat dengan adanya label gizi pada pangan kemasan adalah untuk mengetahui informasi nilai gizi yang tertera dalam kemasan serta mengetahui kebenaran informasi produk terutama produk yang memiliki klaim tentang gizi, kesehatan, ataupun hal lainnya. Selain itu label gizi juga memberikan informasi kepada konsumen dalam memilih pangan yang aman. Membaca label pangan pada produk kemasan dengan benar dan tepat berfungsi untuk melindungi konsumen dari konsumsi pangan yang tidak aman.

\section{KESIMPULAN}

Kebiasaan membaca label gizi dengan kejadian hipertensi pada wanita usia 40 tahun tidak memiliki hubungan yang sigifikan. Diperlukan adanya edukasi kepada produsen dan konsumen terkait pencantuman label gizi pada makanan kemasan yang mudah untuk dipahami oleh konsumen dan dapat dijadikan acuan dalam memilih makanan kemasan. 


\section{ACKNOWLEDGEMENT}

Peneliti mengucapkan terima kasih kepada kepala Balai Desa Modong, warga Desa Modong yang menjadi responden dalam penelitian ini serta teman-teman yang telah membantu dalam penelitian ini. Selain itu, ucapan terima kasih juga diberikan kepada seluruh staff pengajar program Studi S1 Gizi Fakultas Kesehatan Masyarakat Universitas Airlangga.

\section{REFERENSI}

Adilin, M.A.M.H., Nor, F.A.S.., Aliff, A.M.M., Fattin, F.C.A.. \& Syaswani, O.N. 2015, 'Awareness and Its Effects towards Consumer Behaviour in Purchasing Product', Juornal of Applied Environmental and Biological Sciences, vol. 5, pp. 62-8.

Anderson, C.A.M., Appel, L.J., N., O., Brown, I.J., Chan, Q., Zhao, L., Ueshima, H., Kesteloot, H., Miura, K., Crub, J.D., Yoshita, K., Elliott, P., Yamamoyo, M.E. \& Stamler, J. 2010, 'Dietary Sources of Sodium in China, Japan, the United Kingdom, and the United States, Women and Men Aged 40 to 59 Years: The INTERMAP Study', Journal of the Academy of Nutriition and Dietetics, vol. 110, no. 5, pp. 736-45.

Badan Pusat Statistik 2017, Kota Sidoarjo Dalam Angka.

BPOM RI 2005, Badan Pengawas Obat dan Makanan.

BPOM RI 2016, Acuan Label Gizi.

Campos, S., Doxey, J. \& Hammond, D. 2011, 'Nutrition labels on pre-packaged foods: A systematic review', Public health nutrition, vol. 14, pp. 1496-506.

Castillo, L.P., Royo, B.M.. \& Moya, G.. 2012, 'Information Search Behaviour, Understanding and Use Pf Nutritiom Labeling By Residents Of Madrid', Journal Public Health, [e-journal], vol. 12, no. 93, pp. 226-36.

Cowburn, G. \& Stockley, L. 2005, 'Consumer understanding and use of nutrition labelling', Public health nutrition, vol. 8 , pp. $8-21$.

Elfassy, T.Y.., Eisenhower, D., Leaderer, A. \& Curtis, C.J. 2015, 'Use of Sodium Information on the Nutrition Facts Label in New York City Adults with Hypertension', Journal Of The Academy Of Nutrition And Dietetics, vol. 115 , no. 2, pp. 278-83.

Geraci, T.S. \& Geraci, S.A. 2013, 'Consideration in woman with hypertension', Review Article Shoutern Medical Assosiation, [e-journal], vol. 106, no. 7, pp. 434-8.

Hersey, J.C., Wohlgenant, K.C., Arsenault, J.E., Kosa, K.M. \& Muth, M.K. 2013, 'Effects of front-of-package and shelf nutrition labeling systems on consumers', Nutr. Rev., vol. 71, pp. 1-14.

Hussain, M.A., Mamun, A., Al, Reid, C. \& Huxley, R.R. n.d., Prevalence, Awareness, Treatment and Control of Hypertension in Indonesian Adults Aged 40 Years : Findings from the Indonesia Family Life Survey (IFLS), pp. 1-16.

J.E., L., K.L., A., W.G., L., L.E., F., D.J., L., E.P., D., A.J., C.-M., N.A., D., K.E., M., F.C., B. \& J.D., C.J. 2009, 'Food label use and awareness of nutritional information and recommendations among persons with chronic disease', American Journal of Clinical Nutrition, vol. 90, no. 5, pp. 1351-7.

James, P.A., Opari, S., Carter, B.L., Cushman, W.C., Himmelfarb, C.D., Handler, J., Lackland, D.T., LeFevre, M.L., MacKenzie, T.D., Ogedegbe, O., SmithJr, S.C., Svetkey, L.P., Taler, S.J., Townsend, R.R., WrightJr, J.T., Narva, A.S. \& Ortiz, E. 2014, Evidence-Based Guideline for the Management of High Blood Pressure in Adults Report From the Panel Members Appointed to the Eighth Joint National Committee (JNC 8).

Kairupan, C.A. 2013, 'Fungsi dan tugas badan perlindungan konsumen nasional dalam menerima pengaduan mengenai pelanggaran hak-hak konsumen', Lex et Societatis, vol. 1, no. 3, pp. 117-25.

Kemenkes 2014, Infodatin Hipertensi.

Kemenkes RI 2018, Riskesdas tahun 2018.

Kuntoro 2010, Metode Sampling dan Penentuan Besar Sampel, Revisi., Pustaka Melati.

Mahan, L.K. 2017, Krause's Food \& The Nutrition Care Process, Fourteenth., Missouri.

Notoatmodjo 2012, Promosi Kesehatan dan Perilaku Kesehatan, Rineka Cipta.

Palupi, I.R., Naomi, N.D. \& Susilo, J. 2017, 'Penggunaan Label Gizi dan Konsumsi Makanan Kemasan Pada Anggota Persatuan Diabetisi Indonesia Unit RS Kota Yogyakarta', Jurnal Kesehatan Masyarakat, vol. 11, pp. $1-12$.

Prihatini, S., Permaesih, D. \& Julianti, E.D. 2017, 'ASUPAN NATRIUM PENDUDUK INDONESIA: Analisis Data Survei Konsumsi Makanan Individu (SKMI)', Gizi Indonesia, vol. 39, pp. 15-24.

WHO-ISH 2013, 'Guidelines of the management of hypertension', Journal Hypertension, vol. 21, no. 11, pp. 83-92. Zhang, D., Yan, L., Wang, G., Moran, A.E. \& Pagan, J.A. 2017, 'Nutrition Label Use and Sodium Intake In The U.S', American Journal of Preventive Medicine, vol. 53, no. 62, pp. 220-7. 